\title{
No jobs left for the boys
}

A CRISIS is approaching in the employment of scientists in the academic and closely-allied worlds of the UK. Nothing explosive will herald its arrival; there will be no dramatic day on which we shall all wake up to find the newspapers full of it. Rather, over the next few years it is going to be more and more difficult for young people of an academic frame of mind to find a satisfying career. And no-one needs reminding that the influx of young staff is essential to the continued vitality of most academic departments.

The reasons for this crisis have often been discussed in these columns; they stem from three clearly defined factors. First, relatively few people are retiring from university posts at present, or, for that matter, from research-council laboratories or the scientific civil service. The enormous university expansion in the middle 1960 s has left the system with large numbers of people now middle-aged : fewer than $1 \%$ of all university staff retire this year. The civil service has a somewhat more uniform age distribution, but even so less than $2 \%$ retire annually at present.

Second, for the past four years university finances have not allowed vice-chancellors the luxury of filling even such posts as have become vacant without asking the most searching questions about the prudence of taking on a new long-term commitment. The resultant partial freeze on hiring has nudged the student-staff ratio up to around $10: 1$, or from another point of view has called for an increase in the productivity of university staff.

Third, long term projections of student numbers unambiguously point to smaller universities in the 1990s. For the past ten years the decline in the numbers of those of university age (following the post-war baby boom) has been offset by a steady increase in the percentage of these who seek, and are qualified to receive, higher education. This percentage now seems to have peaked and to be in slight decline whilst the numbers in the relevant age group are rising to a new peak in 1981 . For the past ten years then and the next five it seems as if substantial demographic swings will have been moderated by changes in the perceived desirability of going to university, resulting in a slow and controllable expansion in student numbers. But what happens beyond 1981 is anybody's guess. One thing is certain: that by the early 1990 s numbers in the relevant age group will be more than a quarter down on those for the early 1980s. So the problem of adjusting university staffing to cope with this demographic change is a severe one now, and will presumably become even more severe in the late $1980 \mathrm{~s}$ as those educated at the time of the peak start to look for academic posts.

Thus, to get a job in 1977, you need to find someone who is retiring from a university that is not plagued by financial problems and is confident that in the long-term its student numbers will hold up. Needless to say you will not be the only applicant. And you will find the same competitors pursuing the same limited opportunities in research-council establishments. A supply of suitable people in excess of the demand for them must be one of the factors ensuring that low academic salaries hardly pose a headache to the government, despite mass lobbies and palpable inequities.

How do we get ourselves out of this bind, ensuring that bright minds are not wasted? Clearly some specific initiatives, such as support of more young scientists by the Royal Society, help to take a little of the strain. But it is unlikely that the problem will be seriously alleviated without some radical steps being taken-and in present circumstances these steps can hardly be vast expenditures on new laboratories. If they are we run the danger of acquiring yet another group which grows old together and doesn't start to open up further employment opportunities until the year 2010.

The unspectacular alternative (it can hardly be called a solution) is for very serious examination of the knotty problems of tenure and retirement. In the past ten years scientists, reflecting a national trend, have become ever more cautious of any sort of employment which left them without security above the age of 30 , and have then felt safe until the age of 65 . The civil service have, of course, led the way in providing a lifetime of stability. There is certainly a lot of good in buffering scientists from shortterm change, but is the only alternative a thirty-five year guarantee of employment or, put another way, exclusion for thirty-five years of someone else from the same employment? Surely not when times are becoming progressively harder; some new form of contract of employment must be worked out which can respond to the aspirations of young scientists for employment without humiliating senior colleagues who have given a lifetime of service. Talks are already proceeding on these matters between various interested parties-those involved need every encouragement to come up with some flexible proposals as soon as possible. 